\title{
Assessment of Sugarcane Brown Rust (Puccinia melanocephela) Disease Intensity in Finchaa Sugar Estate, Horo - Guduru Wollega, Oromia, Ethiopia
}

\author{
Melka Kecha \\ Department of Plant Science, College of Agriculture, Oda Bultum University, Chiro, Ethiopia \\ Email address: \\ abekecha@gmail.com
}

To cite this article:

Melka Kecha. Assessment of Sugarcane Brown Rust (Puccinia melanocephela) Disease Intensity in Finchaa Sugar Estate, Horo - Guduru Wollega, Oromia, Ethiopia. International Journal of Biochemistry, Biophysics \& Molecular Biology. Vol. 5, No. 2, 2020, pp. 39-43. doi: $10.11648 /$ j.ijbbmb.20200502.14

Received: September 11, 2020; Accepted: September 25, 2020; Published: October 30, 2020

\begin{abstract}
Sugarcane (Saccharum officinarum L.) is an important industrial cash crop. Sugarcane brown rust (Puccinia melanocephela Syd. \& P. Syd) is one of the most devastating diseases. The current study was carried out to assessing the sugarcane brown rust disease intensity in Finchaa Sugar Estate, Ethiopia, during the main cropping season of 2016. The field survey was conducted on sugarcane-cultivated fields of Finchaa Sugar Estate. These fields were under age of five three to eight months. A total of 126 fields were assessed. For the fields three components of disease intensity were assessed i.e. disease prevalence, disease incidence and disease severity. From the three disease, intensity severity is directly related to yield losses of the crop. Among those fields; the disease was prevalent on $123(97.62 \%)$ fields. The result of this survey indicates that the distribution of brown rust severity varies from variety to variety and it was varied with the age of sugar cane crop. The assessed data also showed there were about seven sugar cane varieties and they differ in reaction of sugar cane rust disease. The method of data analysis was descriptive statistics. The mean maximum of disease severity $(22.5 \%)$ was recorded on SP70/1284 variety while the least disease severity (11.0\%) was recorded on the variety C132. An incidence of $95.0 \%$ on SP70/1284 cultivar and $81.5 \%$ were recorded on variety $\mathrm{C} 132$. Generally the report indicated that the appropriate management method should be implemented.
\end{abstract}

Keywords: Sugarcane, Brown Rust, Puccinia Melanocephela, Disease Intensity

\section{Introduction}

Sugarcane, an important cash crop and the source for $80 \%$ of the crystal sugar in the world is grown over more than 110 countries of both tropical as well as subtropical regions up to $30^{\circ} \mathrm{N}$ and $35^{\circ} \mathrm{C}$ latitudes on both sides of equator. Across the world, India ranks second both in area and production after Brazil [1]. Sugarcane is responsible for $\sim 70 \%$ raw table sugar production worldwide [2]. It is usually vegetatively propagated from auxiliary buds on the stalk cuttings. Sugarcane is considered the best biofuel crop in equatorial and tropical regions due to its yield and production costs [3]. The sugar factories are also expected to contribute about 448 megawatt electric power through co-generation [4]. In Ethiopia, sugarcane is the only base material for sugar production and thus the sugar industries in Ethiopia rely on the status of this crop. Sugarcane is an important crop widely cultivated for different purposes by smallholder farmers in sub-Saharan Africa (SSA), including Ethiopia.

In spite of this fact, the country has high production potentials and opportunities which include specifically identified irrigable suitable fertile areas of 1,390,000 ha, favorable weather conditions, cheap and productive labor force, high demand for sugar and other by-products and huge market outlets to the nearby countries [5]. To utilize these opportunities and reverse current situation: satisfy the local sugar demand and export the surplus; the Ethiopian Sugar Corporation is undertaking large scale expansion and new sugar development projects in different regions of the country. 
Despite the importance of sugarcane in the country, the yield of sugarcane is constrained by many environmental and management factors [6] and its production entails an integration of various factors such as weather, water, biotic, soil and economic factors. Diseases, weeds, and insect pests are among the major biotic constraints of sugarcane production [7]. Sugar cane brown rust is an economically important disease in many sugarcanegrowing countries. Yield loss as high as $10-40 \%$ has been recorded in susceptible varieties in some countries [8]. Yield reduction due to sugarcane rust was not quantified in Ethiopia particularly at Finchaa sugar estate but some survey was conducted at Metehara and Kesem [9]. In Ethiopian sugarcane plantations, the leaf area infected percentage that ranges from $5-8 \%$ and $5-15 \%$ has been recorded at Metahara Sugarcane Plantation and Kesem Sugar Project, respectively [10].

The current management practices across the worldwide are using resistant varieties, cultural practices, and chemical control methods [11]. However, in Ethiopia there is no information about the control of sugarcane brown rust disease, since the disease is recently introduced to the country. A 'new' disease in fields of sugarcane variety DB377/60 was first reported in March 2007 in Ethiopian
Sugarcane Research Services Station [12]. The abovementioned sugarcane rust control methods have their own gaps, for example, rusts can be managed by planting resistant cultivars. However, due to the emergence of new races of the rust fungi, the resistance present in current cultivars can be broken [13]. Therefore, this method needs the diversification of the varieties not to break their resistance. In Ethiopia, there are no chemicals evaluated to control sugarcane rust disease. Therefore, the current study was carried out to assess the disease intensity of sugarcane brown rust disease in Finchaa Sugar Estate with the following objectives: to put the baseline information on distribution of disease intensity of sugarcane brown rust disease.

\section{Materials and Methods}

\subsection{Description of the Study Area}

Finchaa Sugar Estate is the third pioneer sugarcane plantation established in 1998. Finchaa Sugar Estate is located in the Finchaa River Valley of Ethiopia at a latitude of $8^{\circ} 31^{\prime} \mathrm{N}$ and longitude of $39^{\circ} 12^{\prime} \mathrm{E}$, respectively with elevation ranging from $1350-1650 \mathrm{~m}$. a. s. 1.

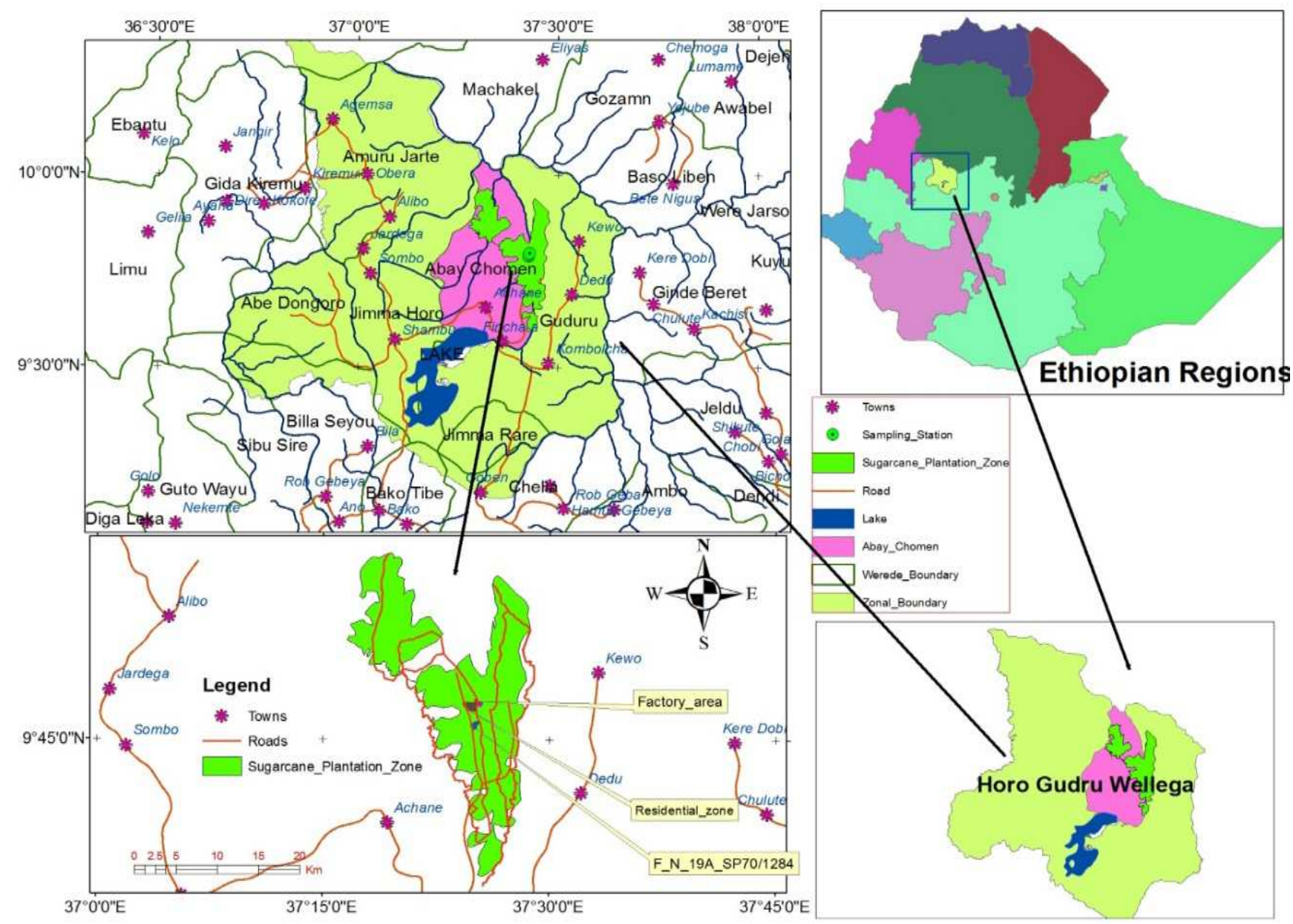

Figure 1. Map of the study area. 


\subsection{Sampling Techniques on Assessment of Sugarcane Rust Disease}

Sugar cane Crop at every growth stage was selected for field surveying to identify the most susceptible growth stage. The sugarcane plant, which is three to eight month, is included in the growth stage of tillering to stalk bearing growth phase. The selected fields of sugar Estate were affected by sugarcane brown rust disease in the country. Random sampling was used to select farm field of sugarcane plants based on its growth stage in each section of Finchaa sugar Estate i.e. every sugarcane field at interval of 5-10 km based on vehicle odometers following the main roads and accessible routes were assessed. The disease assessment was carried in October 2016.

In the selected fields, the disease assessment was made along the two diagonals in an " $\mathrm{X}$ " fashion. Five quadrants were sampled out from the fields considered in the assessment using two furrows $x 1.45 \mathrm{~m}=2.9 \mathrm{~m}^{2}$ quadrant at approximately $20-50 \mathrm{~m}$ far from each other. In each field, plants within the quadrant was counted and recorded as diseased and healthy.

Disease prevalence (\%) was calculated as number of fields affected by sugarcane rust disease the total number of fields assessed and expressed as percentages.

$$
\text { Prevalence }=\frac{\text { Noofinfectedfields } x 100}{\text { Totalnooffieldsassessed }}
$$

Disease incidence was calculated as the percentage of infected plants to the total number of plants counted per spot.

$$
\begin{gathered}
\text { Incidence }=\frac{\text { Totalnumberof diseasedplants } x 100}{\text { Totalnumberofplantsassessed }} \\
\text { Disease severity }=\frac{\text { Area of plant tissue affected } x 100}{\text { Total area of the plant }}
\end{gathered}
$$

\subsection{Data Collection}

The disease prevalence is calculated from the fields under assessment. Disease incidences were recorded from the plants found in the spots and disease severities were recorded from 10 plants in the middle 4 rows of each spot. The incidence and severity of the fields were calculated according to the methods/formula, which is mentioned in 3.2 section [14].

\subsection{Data Analysis}

Data on sugarcane rust disease incidence, prevalence, severity, were subjected to analysis of variance (ANOVA) to determine the treatment effect on dependable variables using SAS statistical software package (SAS, 2003). Least significant difference (LSD) was used for mean separation.

\section{Results and Discussion}

\subsection{Assessment of Disease Intensity}

Field survey of sugarcane brown rust disease was carried out in the main growing season of the selected fields of Finchaa sugar Estate of Horo- Guduru Wollega zone of Oromia region in October 2016 at the tillering stage of sugarcane growth phase. Sugarcane, which was between 5-8 months, can be stated with tillering to stalk bearing stage of sugarcane growth phase [15]. The sugarcane plant that was susceptible for sugarcane brown rust disease is at the growth stage of tillering to stalk bearing i.e. three months to eight months [16]. The study area was purposively selected due to its exposure to the stated disease. A total of 126 sugarcane fields that includes 40 fields N-14 sugarcane variety, 15 fields from D42/58 sugarcane variety, 25 fields from SP70/1284 variety, 10 fields from B80/250 sugarcane variety, 13 from C86/56 sugarcane variety, 9 fields from $\mathrm{C} 132$ sugarcane variety and 14 fields from NCO334were surveyed. During the assessment, sugarcane brown rust disease was observed on $123(92.5 \%)$ of the surveyed fields and it was higher on SP70/1284 variety $(100 \%)$ than the rest of sugarcane varieties followed by $\mathrm{N}-14$ sugarcane variety $(92.5 \%)$. The survey results indicated that there is high in disease severity, incidence and prevalence in Finchaa sugarcane cultivation field (Table 1).

From the survey results, one spot in average had 69-110 stalks i.e. 5948-9482 stalks per hectare depending on the varieties. The result of survey showed that about $97.62 \%$ of disease prevalence, which means almost all the fields were infected by sugarcane brown rust disease even if the extent is varied among the varieties and about $30 \%$ of disease severity was recorded during the survey. Similarly, [17] reported that the brown rust disease recorded in the three sugar estates (Wonji, Metahara and Finchaa) sugarcane plantations in Ethiopia. In Ethiopian sugarcane plantations, the leaf area infected brown rust percentage that ranges from $5-8 \%$ and 5 - $15 \%$ were recorded at Metahara Sugarcane Plantation and Kesem Sugar Project, respectively [18].

Table 1. Sugarcane brown rust disease intensity in percentage from the results among the varieties conducted at Finchaa sugar Estate.

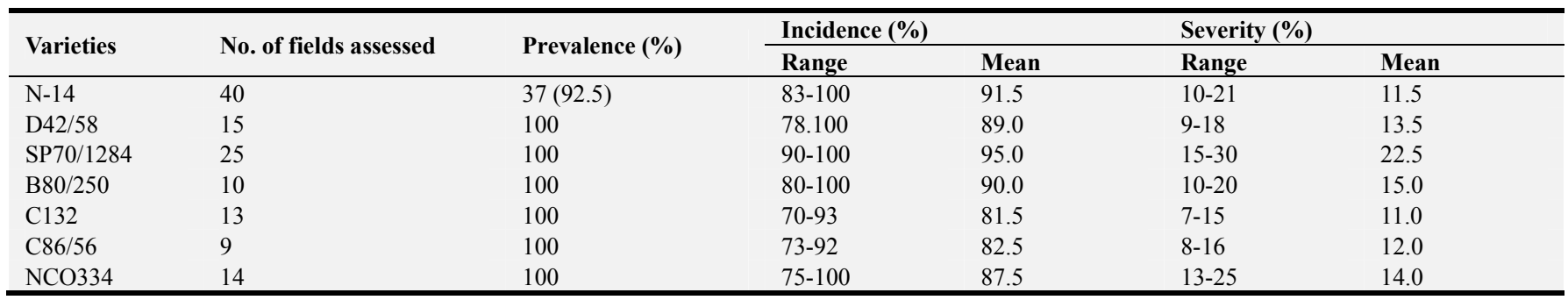


The survey results stated that sugarcane brown rust disease incidence ranges from $70-100 \%$ (Table 1). The highest mean of disease incidence and severity was recorded in SP70/1284 variety with the mean of $95.0 \%$, and $22.5 \%$, respectively. The least mean disease incidence and severity were recorded in $\mathrm{C} 132$ with mean of $81.5 \%$ and $11.0 \%$, respectively.

\subsection{The Development of Sugar Cane Brown Rust Disease}

Many factors influence the development of brown rust on a susceptible host. The most important factors are leaf wetness and temperature [19]. The results of this survey indicated that, the intensity of sugarcane brown rust increases starting from the time of infection up to crop maturity i.e. from 5-8 month old. The time of infection for sugarcane brown rust disease most probably starts from two months and increases up to seven months depending on environmental conditions. However, after the $7^{\text {th }}$ month sugarcane rust disease severity starts to decline as indicated on (Figure 1). Temperature are necessary for spore germination, infection and subsequent spread of the disease. The disease is more severe in younger plants with plants between two and six months being most susceptible [20].

\section{Summary and Conclusions}

Ethiopia has a suitable area of land for the production of sugarcane and planned to be one of the major producers of sugarcane crop. The low productivity of the crop in the country is attributed to susceptibility to biotic and a biotic stresses. Brown rust disease has become a serious threat to sugarcane production and productivity in major sugarcane growing areas of the country causing a yield loss as high as $52.01 \%$. The present study was carried out to assess the intensity of sugarcane brown rust disease and to quantify the incidence and severity of brown rust. Field survey was carried out in nine sections of Finchaa sugar Estate. Among the total number of fields (126) surveyed, the disease was observed in $123(97.62 \%)$ of the surveyed fields with mean incidence and severity of 95.0 and $22.5 \%$, respectively. The highest mean diseases severity $(18.08 \%)$ was recorded on the cultivar SP70/1284 while the least $(9.63 \%)$ was recorded on the cultivar C132.

\section{Recommendations}

Sugarcane brown rust disease was reported in March 2007 to the country, its spreads at alarming rate in most of the major sugarcane growing areas of the country.

Thus, further management/control of this disease should be aimed at reducing the crop losses and check the spread of the disease to new areas. For the development of sound and successful management, information regarding on epidemiology of the disease in the country is a paramount. Thus, any research towards this line could be highly appreciated/ recommended.

\section{References}

[1] Selvakumar R, Viswanathan R (2017) Influence of weather parameters on sugarcane brown rust development in peninsular India pp317-320 In: International Symposium on sugarcane Research since Co 205: 100 years and beyond Ed Hemaprabha, G, Viswanathan, R, Ramasubramanian, T, Bhaskaran, A, Mohanraj, K and Bakshi Ram (Sucrosym 2017), Coimbatore, India.

[2] FAO (2019) http://fenixfaoorg/faostat/internal/en/?\#data/QC.

[3] Contreras, A. M.; Rosa, E.; Pérez, M.; van Langenhove, H. \& Dewulf, J. (2009). Comparative Life Cycle Assessment of Four Alternatives for Using By-products of Cane Sugar Production. Journal of Cleaner Production, Vol. 17, No. 8, (May 2009), pp. 772-779, 09596526.

[4] Goldemberg, J. (2010). The State of São Paulo Strategy for Fuel Ethanol, In: Sugar Cane Bioethanol: R\&D for productivity and sustainability, L. A. B. Cortez (Ed.), 19-26, Blucher, ISBN: 9788521205302, São Paulo.

[5] Ethiopian Sugar Corporation (ESC). (2013). Sugar Corporation and Ethiopian Sugar Industry Profile. Retrieved March 12, 2016, from http://www.etsugar.gov.et/index.php/en/.

[6] ESDA (Ethiopian Sugar Development Agency) (2015/162019/20). Addis Ababa: National Planning Commission Federal Democratic Republic of Ethiopia, 2015/16. [Google Scholar].

[7] Rott P (2018) Achieving sustainable cultivation of sugarcane Volume 1, Achieving sustainable clones to brown rust in the field pp 90 In: ISSCT XII pathology workshop, Sep 3-7, 2018, Coimbatore, India P 90.

[8] Abera T et al., 2009. Review of sugarcane protection research in Ethiopia. pp. 409-447. In: Abraham T. (ed.) Increasing crop production through improved plant protection: Vol. 2. Plant Protection Society of Ethiopia, Addis Ababa, Ethiopia.

[9] Raid, R. N., and Comstock, J. C. 2006. Sugarcane Rust Disease. University of Florida, Florida Sugarcane Handbook.

[10] (Puccinia melanocephela Sydow). Taiwan Sugar 108: 25-33. Jones I. T. and Davies I. J. E. R. 1985. Partial resistance to Erysiphegraminishordeiin old European barley varieties. Euphytica 34: 499-457.

[11] Madden LV (1983). Measuring and modeling crop losses the field level. Phytopath 73: 1591-1596.

[12] Raid RN, Rott PC, Comstock JC (2015) Varietal resistance to sugarcane rusts in Florida: A historical perspective and future prospects Page 6 in: Abstract of the XIth Pathology and IXth Entomology Workshops, September 14-18, Guayaquil, Ecuador.

[13] Barnes, A. C. 1964. The Sugarcane, Botany, Cultivation and Utilization: L. Hill Ltd. London-New.

[14] Central Statistics Agency (CSA). (2013). Agricultural sample survey: Area and production: private peasant holdings. Ethiopia: Statistical Bulletin. 
[15] Aime MC (2006) toward resolving family-level Anderson, D. L., Raid, R. N., Irey, M. S., and Henderson, L. J. 1990. Association of sugarcane rust severity with soil factors in Florida. Plant Disease 74: 683-686.

[16] Bernard F. A. 1980. Considerations of the appearance of sugarcane rust disease in the Dominican Republic. Proceedings of the International Society of Sugar Cane Technologists' Congress 17: 1382-1386.

[17] Grisham, M. P., Johnson, R. M., Richard Jr, E. P. 2006. Effect of soil properties on sugarcane brown rust incidence and severity and associated yield loss [abstract]. Phytopathology. 96: S43.
[18] Holland, J. B., and Munkvold G. P. 2001. Genetic relationships of crown rust resistance, grain yield, test weight, and seed weight in oat. Crop Science 41: 1041-1050

[19] ICUMSA (International Commission for Uniform Methods of Sugar Analysis); www.icumsa.org (access 05/18/2012). Improvement through breeding. Elsevier publication, Amsterdam, Netherland, 11: 7-84.

[20] Institute Brasileiro De Geography E statistician. 2008. Agricultural producer municipal. 2002. 